\title{
Centro de planejamento da UnB: aspectos históricos, mapeamento dos níveis de deterioração na estrutura e propostas de intervenção
}

\author{
UnB's planning center: historical aspects, structural \\ pathology mapping and intervention proposals
}

\begin{abstract}
Tiago Ferreira Campos Neto
J éssica Brandão Faria

J osé Manoel Morales Sánchez

J oão da Costa Pantoja

\section{Resumo}

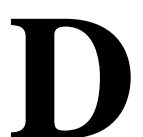

urabilidade é a capacidade de a estrutura se manter em condições plenas de utilização, não devendo apresentar danos que comprometam em parte ou totalmente o uso para o qual foi projetada. A construção do Pavilhão de Serviços Gerais 10 (SG-10) foi baseada em paredes de elementos pré-moldados em forma de "U” e cobertura de vigas pré-moldadas e protendidas. Desde o período de sua construção não se tem registro de intervenções que tenham sido realizadas de forma a prolongar sua vida útil. Partindo desse contexto, e sabendo que o conjunto de pavilhões de Serviços Gerais compreende edifícios representativos da Universidade de Brasília, este artigo tem o objetivo de avaliar a condição da estrutura de concreto do SG-10, mapear os níveis de deterioração dos elementos e apresentar propostas de intervenção. Como método de avaliação utilizou-se o Roteiro de Inspeções, que inclui a metodologia GDE/UnB (FONSECA, 2007) como base de quantificação de dano. Após a aplicação da metodologia verificou-se que o edifício do SG-10 precisa passar por um processo imediato de intervenção, sendo necessária a realização de serviços de recuperação da estrutura.

Tiago Ferreira Campos Neto Universidade de Brasília Goiânia - Goiás - Brasil

J éssica Brandão Faria Universidade de Brasília Brasília - DF - Brasil

J osé Manoel Morales Sánchez Universidade de Brasília Brasília - DF - Brasil

J oão da Costa Pantoja Universidade de Brasília Brasília - DF - Brasi

Recebido em 09/03/17

Palavras-chave: Durabilidade. SG-10. Metodologia GDE/UnB. Propostas de intervenção.

\section{Abstract}

Durability is the ability of the structure to remain in full conditions of utilization, without presenting showing damage that could compromise partly or totally the use for which it was designed. The construction of SG-10 was based on precast walls in form of " $U$ " and coverage of precast prestressed beams. Since its construction has no record of interventions that have been undertaken in order to prolong its service life. Based on this context, and knowing that the set of General Departments pavilions comprises representative buildings of UnB, this article aimed to assess the condition of the SG-10 concrete structure and map the deterioration levels of the elements and present intervention proposals. As an evaluation method was used the Inspections Guide that includes the GDE/UnB methodology as a basis for quantifying damage. After applying the methodology, it was found that the building needs to undergo an intervention process immediately, once recovery services need to be performed.
\end{abstract}

Aceito em 10/11/17
Keywords: Durability. SG-10. GDE/UnB methodology. Intervention proposals. 


\section{Introdução}

Entre os anos de 1963 e 1965 foi construído o Pavilhão de Serviços Gerais 10 (SG-10), que abriga o Centro de Estudos e Planejamento Arquitetônico e Urbanístico (Ceplan) da Universidade de Brasília (UnB). O edifício foi criado com o objetivo de prover à jovem universidade, naquela época, um órgão de assessoria técnica coordenado por Oscar Niemeyer, tendo Lúcio Costa e Joaquim Cardozo como consultores (FONSECA, 2007). Atualmente, além do Centro de Planejamento, o pavilhão abriga em parte de seu espaço o Núcleo de Dança. A Figura 1 apresenta a vista do conjunto de Serviços Gerais retratada na década de 70 (destaque para o SG-10) e uma fotografia atual da edificação.

O então chamado Centro de Planejamento Oscar Niemeyer foi projetado pelo arquiteto que lhe dá o nome, entretanto o desenvolvimento do projeto arquitetônico foi realizado em parceria com o arquiteto João da Gama Figueiras Lima e construído pela empresa Rabello S.A. O pavilhão SG-10 está localizado no Campus Darcy Ribeiro, na Gleba A da instituição, e possui área construída de $1.203 \mathrm{~m}^{2}$. É considerado o mais importante dos edifícios que formam o conjunto de Serviços Gerais e, provavelmente, um dos mais belos da instituição. Sua beleza é reflexo da simplicidade visível no projeto de arquitetura e da tecnologia construtiva (SCHLEE et al., 2014).

A proposta original foi concebida considerando o uso do edifício apenas para instalações do Ceplan, conforme apresentado na Figura 2. No entanto, ainda na fase de concepção projetual, o edifício passou a incluir o Núcleo de Dança/Vivência, apresentando o leiaute da Figura 3. O projeto revisado atual, utilizado como base das vistorias, data de outubro de 2010.

Figura 1 - Vista do conjunto de Serviços Gerais (a) e fotografia atual do SG-10 (b)

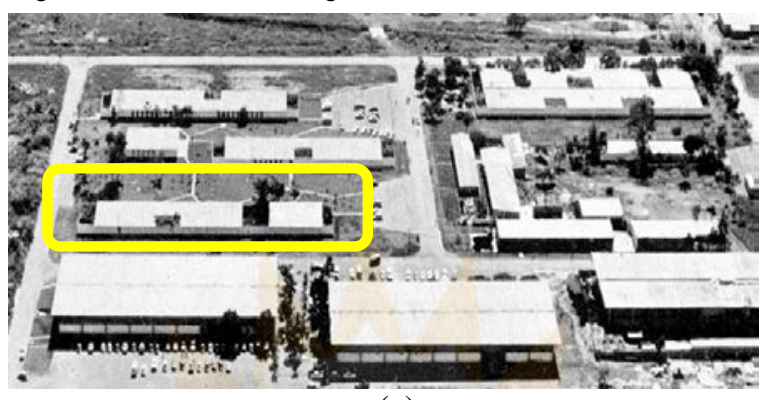

(a)

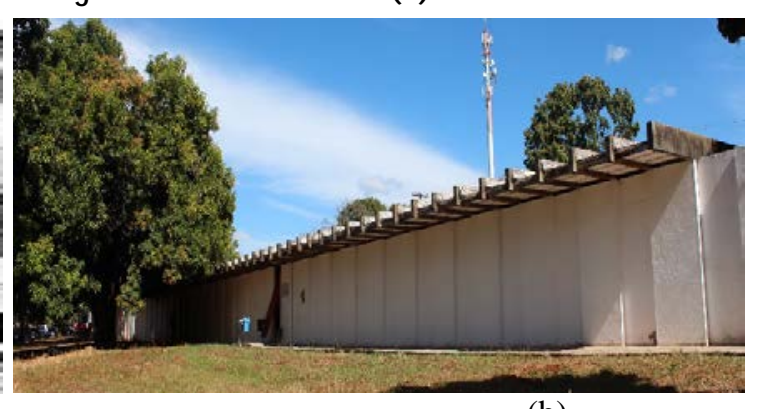

(b)

Fonte: (a) Niemeyer (1970) e (b) autoria própria (2016).

\section{Figura 2 - Planta do Ceplan}

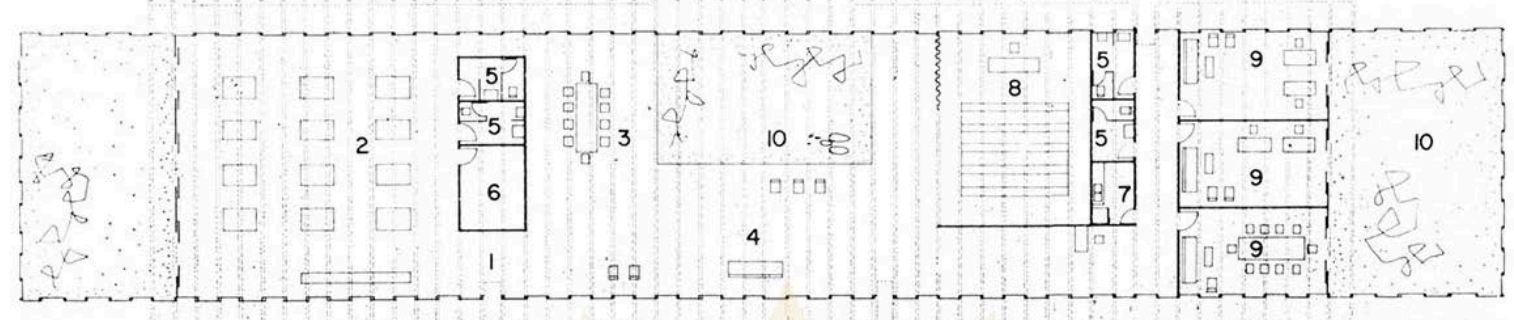

Fonte: Niemeyer (1970).

Nota: Legenda:

1. Hall;

2. Sala de desenho;

3. Reuniões;

4. Exposições:

5. Sanitários;

6. Copiadora;

7. Copa;

8. Auditório;

9. Direção; e

10. Jardim. 
Figura 3 - Planta atual do pavilhão SG-10
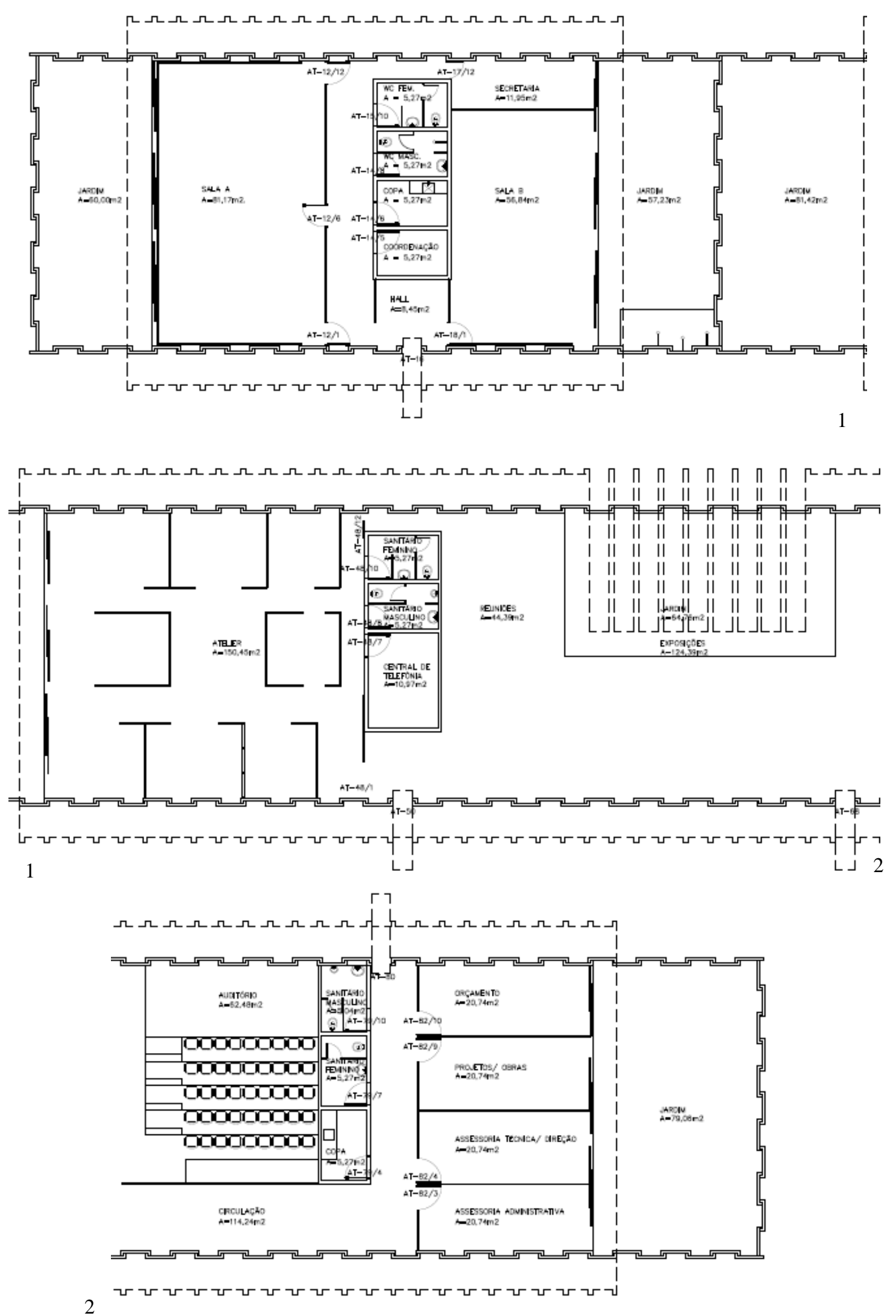

Fonte: Prefeitura do Campus (2016). 
A construção dos pavilhões foi baseada em paredes de elementos pré-moldados em forma de "U" (Figura 4a) e cobertura de vigas pré-moldadas e protendidas (Figura 4c), com recobrimento de alumínio e isolamento térmico-acústico na face interna, vinculadas às paredes conforme ilustrado na Figura 4b (NIEMEYER, 1970). O projetista afirma que em decorrência da natureza das atividades que seriam exercidas nos pavilhões, que exigiriam ambientes de tranquilidade e concentração, os edifícios foram fechados para o exterior e pátios internos garantiriam a intimidade desejada e assegurariam o controle favorável do microclima. Tal sistema construtivo foi adotado com o objetivo de reduzir o prazo de concepção e execução dos pavilhões, atendendo às necessidades da instituição, que na época precisava expandir suas instalações.

Desde o período de sua construção não se tem registro de intervenções que tenham sido realizadas de forma a prolongar sua vida útil, salvo renovação das pinturas.

Segundo Trentin (2005), no conjunto de bens culturais produzidos pela humanidade, a arquitetura constitui um testemunho excepcional na formação da memória histórica dos povos e na formação da identidade. Ela é testemunho sedimentado e acumulado dos modos de vida do homem, não só daqueles que a conceberam na origem, mas também dos que ali viveram através dos tempos e lhe conferiram novos usos e significados. A arquitetura é carregada de sentimentos de gerações, acontecimentos públicos, tragédias, fatos novos e antigos. Portanto, é imprescindível preservá-la e incorporá-la na vida da cidade.

Partindo desse contexto, e sabendo que o conjunto de pavilhões de Serviços Gerais compreende edifícios representativos da Universidade de Brasília, este artigo tem o objetivo de avaliar a condição da estrutura de concreto do SG-10 e apresentar prazos e propostas de intervenção.

\section{Sistema construtivo do SG-10}

Possuindo base retangular, desenvolve-se a partir da repetição e associação contínua das placas de vedação (módulos) em “U” - com 1,0x3,0 m -, formando as paredes externas e definindo o pédireito, de 3,0 m. As vigas protendidas de cobertura possuem 15,0 m de comprimento e uma seção transversal igual a 0,12x0,40 m. Em planta, a forma retangular do pavilhão é compreendida por 11 módulos em cada uma das fachadas no menor sentido e 95 em cada uma das fachadas no maior sentido, nos quais são apoiadas as vigas, o que permite um vão de livre de aproximadamente 12,0 m (SCHLEE et al., 2014). O espaço entre vigas foi preenchido por chapas planas de alumínio, cortadas, dobradas e encaixadas, configurando a cobertura do prédio, que tira partido da contraflecha das vigas para o escoamento das águas pluviais.

No edifício são utilizados diferentes tipos de placas, sendo o tipo determinado pela largura e armadura do módulo. O tipo "A” é o mais utilizado, e seus detalhes estão apresentados na Figura 5, em conjunto com o detalhe das vigas. O projeto de estrutura é de responsabilidade da equipe Sermarso S.A., e a execução do edifício ficou sob a responsabilidade da Construtora Rabello S.A.

$\mathrm{Na}$ parede que delimita a sala de reuniões, Niemeyer elaborou um grande painel, no qual reproduziu a Praça Maior da universidade. Já na parede do auditório reproduziu a Praça dos Três Poderes. O aspecto exterior do prédio é marcado por sua horizontalidade e pela repetição dos elementos estruturais brancos, homogeneidade só quebrada pela presença de portas de ferro vermelhas.

Algumas modificações foram realizadas, uma das quais a inserção de um sistema de forro de gesso instalado nas vigas por meio de perfis metálicos que, atualmente, apresentam uma série de manifestações patológicas. Em outros pavilhões, como o SG-4 (Departamento de Música), a estrutura das placas de vedação foi simplesmente recortada para instalação de equipamentos condicionadores de ar do tipo split. Tais recortes foram executados sem critérios de conservação da edificação, pois acabaram por expor as armaduras à ação das intempéries.

No pavilhão SG-10, assim como nos outros edifícios do conjunto, foi executado um sistema de impermeabilização com manta asfáltica sobre as placas de alumínio da cobertura. Esse sistema, assim como a maioria dos sistemas da edificação, não passa por manutenções regulares e preventivas, o que gera inúmeros pontos de infiltração nas vigas, chegando a apresentar lixiviação proeminente nas faces inferiores.

O edifício tem toda sua representatividade arquitetônica fundamentada na expressão de sua forma estrutural. A estrutura é responsável pela forma do edifício, bem como sua imagem, ficando completamente exposta à ação de intempéries. A deterioração da estrutura de concreto influencia na integridade da obra, mas não impacta nos valores de memória e nos sentimentos daqueles que com ela viveram, vivem e viverão momentos. Nesse contexto, os estudos de durabilidade das estruturas de concreto ganham importância e são fundamentais para a conservação da edificação e da memória social. 
Figura 4 - Construção e croqui do sistema construtivo

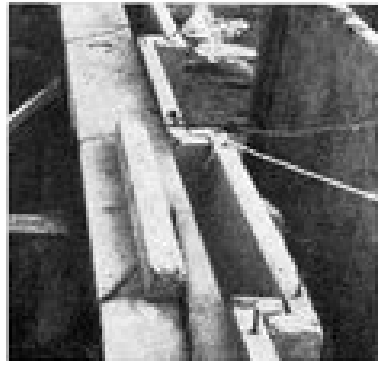

(a) Sistema de instalação das placas de vedação

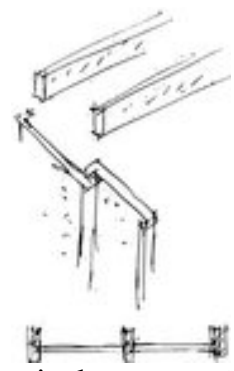

(b) Croquis de concepção feitos por Niemeyer

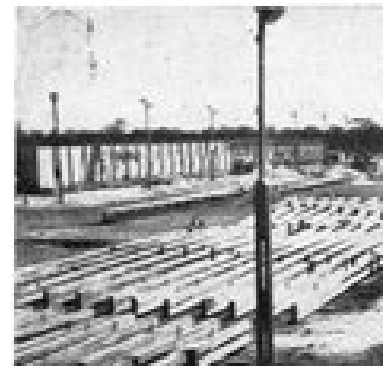

(c) Produção das vigas prémoldadas protendidas

Fonte: Niemeyer (1970).

Figura 5 - Detalhes construtivos da placa de vedação (a) e da viga (b)
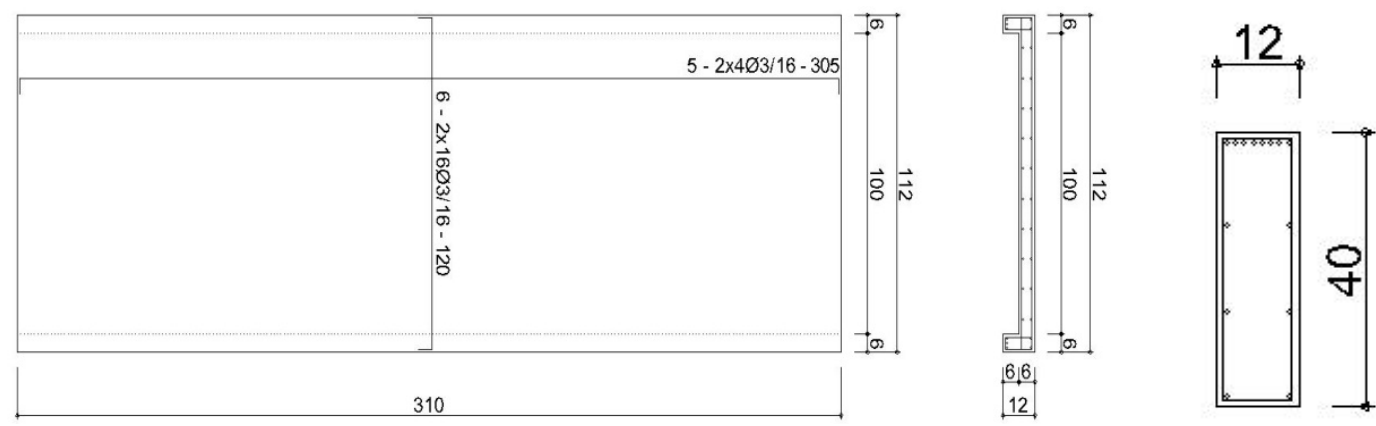

Fonte: adaptada do projeto original de Sermarso S. A. fornecido pela Prefeitura do Campus Darcy Ribeiro da UnB (2016).

\section{Durabilidade e conservação da estrutura do SG-10}

A NBR 6118 (ABNT, 2014) denomina durabilidade como a capacidade de a estrutura manter-se em condições plenas de utilização, não devendo apresentar danos que comprometam em parte ou totalmente o uso para o qual foi projetada. Já a vida útil representa o período durante o qual se mantêm as características das estruturas de concreto, desde que atendidos os requisitos de uso e manutenção prescritos pelo projetista e pelo construtor, bem como de execução de reparos necessários decorrentes de danos acidentais. Dessa forma, para preservar as intenções de projeto de Niemeyer e manter a edificação em condições de utilização é preciso que a cultura da manutenção - fundada em técnicas de correção das causas e efeitos das manifestações patológicas - faça parte do ciclo de vida da edificação em estudo.

Até a década de 1970 condicionantes que tratam de durabilidade e vida útil não tinham grande relevância. Com o passar dos anos, inúmeras edificações apresentavam precocemente processos de deterioração avançados em suas estruturas. Diante da incidência recorrente desses problemas, parâmetros como durabilidade e vida útil passaram a ser considerados em normas brasileiras (FONSECA, 2007).

Uma edificação deve resistir a diversas agressões ou solicitações (físicas, mecânicas, químicas) ao longo do tempo, ou seja, as cargas às quais está submetida e as ações diversas, como ventos, chuvas e variações de temperatura, conservando sua estética e desempenho. Além desses vetores, a obra deve satisfazer constantemente os requisitos dos usuários ao longo de sua vida útil (ROUGEAU; GUIRAUD, 2014).

No pavilhão SG-10 os estudos de durabilidade significam um desafio importante a ser vencido, pois o edifício tem grande representatividade histórica; faz parte da memória de alunos, professores e funcionários da instituição. Seu peso histórico e a falta de planos de manutenção preventiva orientados por profissionais especializados fazem do SG-10 um estudo de caso de destaque para a aplicação de propostas de intervenções fundamentadas em metodologias de avaliação da condição de sua estrutura.

A durabilidade esperada de uma estrutura deve ser assegurada por um projeto adequado, por uma seleção pertinente de materiais e pela qualidade de execução. Embora essa seja uma regra geral, 
defeitos são frequentemente apresentados. Alguns deles podem ser detectados na fase de execução e aceitação da estrutura e, sempre que possível, eliminados. Outros não podem ser eliminados por completo, e outros, ainda, se manifestam apenas depois de muito tempo. Nas estruturas de concreto armado, a redução da durabilidade pode ser causada pela deterioração do concreto, do aço da armadura ou da combinação das duas dimensões (CZARNECKI; WOYCIECHOWSKI, 2013).

De forma a mapear as manifestações patológicas existentes no SG-10, os resultados são apresentados a seguir em categorias de projeto, execução, uso e deterioração natural. Na categoria de projeto são apresentadas manifestações que surgiram em qualquer período e que poderiam ser contornadas na etapa de concepção projetual; na categoria de execução são listadas manifestações resultantes de falhas no processo executivo; na categoria de uso são apresentadas manifestações decorrentes do uso inadequado da edificação; e na categoria de deterioração natural são ordenadas manifestações que surgiram em decorrência do tempo, da exposição do edifício às intempéries e da falta de manutenção.

A deterioração do concreto armado ou protendido deve ser vista sob duas vertentes, pois o processo de deterioração do concreto é diferente do da armadura. Processos físicos, químicos e biológicos podem deteriorar estruturas de concreto armado, entretanto a corrosão é uma das manifestações de maior responsabilidade pela fragilização das armaduras. Sabe-se que o processo de corrosão está diretamente vinculado a processos de deterioração da camada superficial de concreto que as protege, mantendo-as em condição passiva (Figura 6).

Conforme a NBR 5674 (ABNT, 2012), a manutenção deve ter o objetivo de preservar o desempenho previsto em projeto, minimizando a depreciação patrimonial; estabelecer as informações pertinentes e o fluxo da comunicação; e estabelecer as incumbências e autonomia de decisão dos envolvidos. Na organização da gestão do sistema de manutenção deve ser prevista infraestrutura material, técnica, financeira e de recursos humanos capaz de atender aos diferentes tipos de manutenção necessários, que são: manutenção rotineira, caracterizada pelo fluxo constante de serviços, como limpeza geral e lavagem das áreas comuns, já realizados na edificação em estudo; manutenção preventiva, caracterizada por serviços programados antecipadamente, priorizando as solicitações dos usuários, estimativas de durabilidade do edifício e relatórios periódicos sobre o estado de deterioração, como apresentado no método deste artigo; e manutenção corretiva, caracterizada por serviços de ação ou intervenção a fim de permitir a continuidade do uso do edifício de forma a evitar prejuízos pessoais e/ou patrimoniais, conforme apresentado nos resultados deste trabalho. Deve ser acrescido que a execução de um dos tipos de manutenção não exclui a necessidade de execução de qualquer outro tipo.

Moreira (2011) lista uma série de desafios voltados à conservação da arquitetura, sendo grande parte deles de âmbito social. Entretanto, o autor apresenta alguns pontos importantes que dependem da atuação de engenheiros capacitados para a elaboração de planos de ação e execução de técnicas de conservação. Entre esses desafios, podem-se citar:

(a) a dimensão do material dos edifícios, que inclui problemas como o uso de materiais novos sem tradição construtiva;

(b) a falta de entendimento do desempenho dos materiais em longo prazo, de forma a prolongar a vida útil das edificações; $\mathrm{e}$

(c) as falhas de construção e a ausência da cultura de manutenção, que afeta diretamente os edifícios em concreto.

O pavilhão SG-10 foi construído no início da década de 1960, quando os conhecimentos acerca das dimensões do concreto armado e protendido eram limitados, e pouco se pensava no comportamento e desempenho do material no longo prazo. A norma de projeto e execução de estruturas de concreto vigente na época era a Norma Brasileira 1, de 1960 (NB-1/60), que contava com sete capítulos focados apenas em cálculo estrutural (esforços solicitantes, resistentes e tensões admissíveis), disposições construtivas, execução e materiais, sem incluir critérios relacionados à durabilidade das edificações.

O cobrimento das armaduras das placas de vedação apresenta valores dentro dos especificados pela NB1 (1960), sendo igual a $1,50 \mathrm{~cm}$ para as placas e a 2,0 cm para as vigas, ambas expostas ao ar livre. No entanto, esses valores são inferiores aos estabelecidos pela norma atual, NBR 6118 (ABNT, 2014), que determina a proteção da armadura em função da classe de agressividade do meio ambiente - inclusão dos critérios de durabilidade das estruturas -, isto é, 3,0 cm para vigas e pilares. Foi somente a partir de 2003, em uma revisão da norma, que os parâmetros de durabilidade começaram a ser exigidos desde a concepção do projeto. 
Figura 6 - Relação entre conceitos de durabilidade e desempenho das estruturas

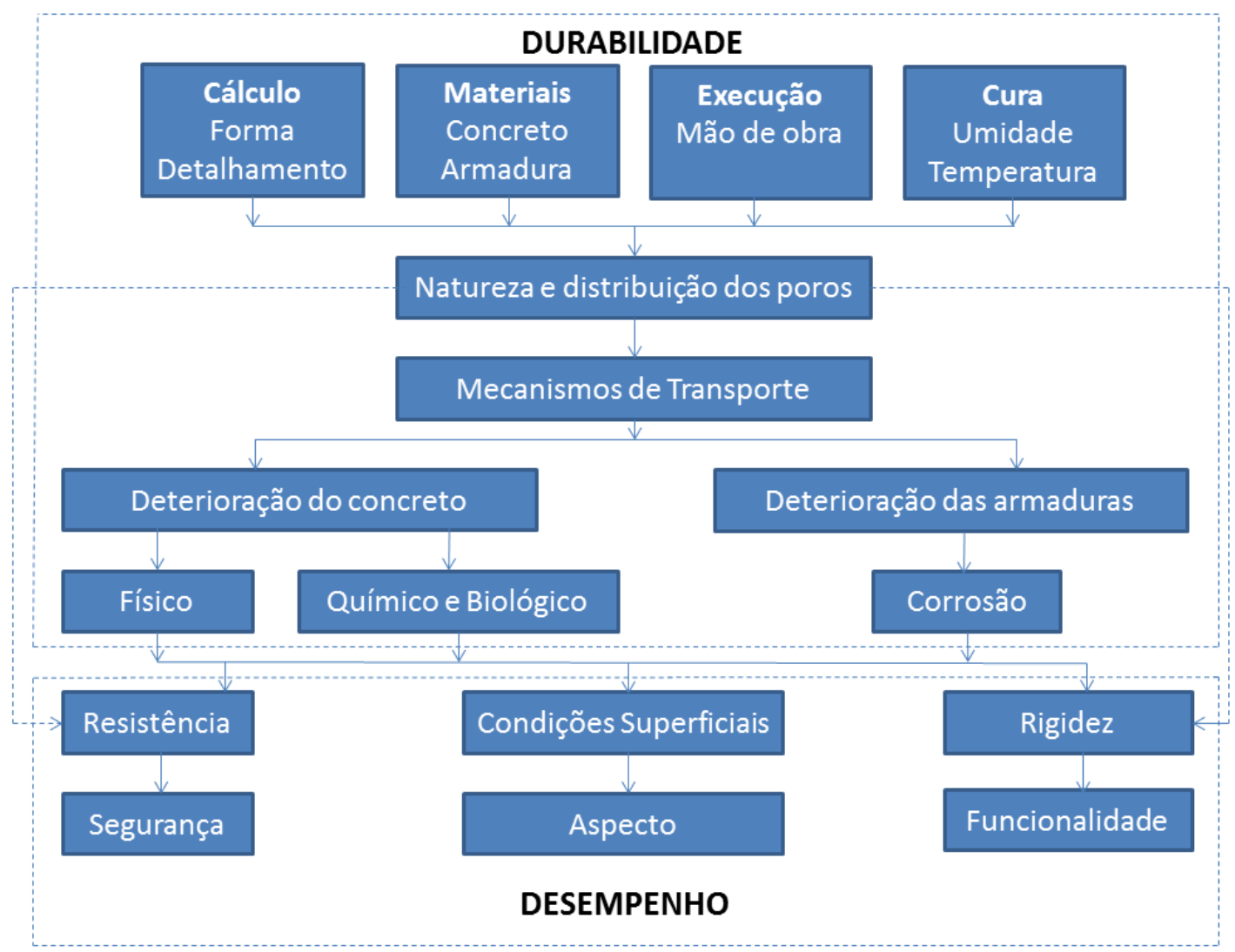

Fonte: adaptada de CEB Bulletin 183 ( $1989^{1}$ apud SOUZA; RIPPER, 2009).

O sistema de manutenção da Universidade de Brasília tem sido realizado de maneira deficiente, pois na Prefeitura do Campus não há registros de planos de ação de manutenções preventivas e corretivas executadas no edifício, estando registrados apenas pequenos reparos conforme solicitações dos usuários, condizentes com manutenções rotineiras.

\section{Método}

Para Castro (1994), a primeira etapa para se definirem a(s) causa(s) de intervenção deverá ser a elaboração de um diagnóstico, que visa determinar o estado atual de uma estrutura, através de inspeções, levantamento de dados, testes e estudos dela. Dependendo da natureza e da extensão da “doença”, as intervenções usuais, na prática, podem incluir uma ou várias das seguintes situações:

(a) avaliação estrutural: determinação das condições e características mecânicas da estrutura;

(b) reparo: recuperação/restabelecimento das características mecânicas iniciais da estrutura; (c) substituição: demolição e reconstrução de elementos fortemente danificados;

(d) reforço: estabelecimento de capacidade de resistência superior à inicial da estrutura; e

(e) reprojeto: procedimento de projeto relativo a intervenções.

\section{Metodologia de avaliação estrutural}

Como método de estudo utilizou-se o Roteiro de Inspeções adaptado por Fonseca (2007) para caracterização da estrutura do Instituto Central de Ciências (ICC) da Universidade de Brasília. A metodologia de avaliação estrutural utilizada é chamada de Grau de Deterioração da Estrutura (GDE/UnB). Algumas das principais modificações realizadas por Fonseca (2007) se concentraram em reformulações da forma de conceituação dos danos, reformulações dos fatores de intensidade associados ao dano de corrosão, reformulação dos fatores de ponderação e reformulações nos níveis de deterioração da estrutura e do elemento.

${ }^{1}$ COMITE EURO-INTERNATIONAL DU BETON. Bulletin D'Information $\mathbf{n}^{\circ} \mathbf{1 8 3}$ : durable concrete structures. Suíça: Thomas Telford Services Ltd, 1992. 
A metodologia GDE/UnB foi aplicada em um edifício pela primeira vez por Castro (1994), no prédio da Faculdade de Tecnologia da UnB, em que se obteve como resultado a classificação "médio" para o nível de deterioração. Boldo (2002) adaptou a metodologia e quantificou quarenta edificações pertencentes ao Exército brasileiro, mostrando que naquele período as edificações estavam, em geral, bem conservadas e apresentavam manifestações de danos visíveis com lesões toleráveis. Fonseca (2007) fez nova adaptação e a aplicou no Instituto Central de Ciências da UnB, tendo obtido como resultado a classificação "sofrível", estando próximo ao intervalo de nível "crítico". Esse breve histórico mostra que a metodologia tem sido estudada e aperfeiçoada, o que mostra o interesse dos profissionais em conservar as edificações.

De acordo com o resultado obtido por meio das vistorias, que consideram padrões estéticos, funcionais e de estabilidade dos elementos estruturais, a metodologia GDE/UnB define alguns valores para serem usados como base de cálculo, chamados de fator de ponderação de dano (Fp), que varia de 1 a 5; e de fator de intensidade (Fi), que indica as possíveis manifestações patológicas que os elementos apresentam, podendo variar de 0 (o elemento estrutural não apresenta lesões) a 4 (o elemento se encontra em estado crítico). O grau de cada dano nos elementos é calculado através de Fp e Fi (Figura 7).

A aplicação da metodologia GDE/UnB se inicia pelo preenchimento da ficha descritiva da edificação. A Figura 8 apresenta a ficha do pavilhão SG-10. Na etapa seguinte deve ser realizada a avaliação da agressividade ambiental à qual a edificação está exposta, conforme especificações da NBR 6118 (ABNT, 2014). O Ceplan está localizado em uma região urbana, portanto pertence à classe II (moderada) de agressividade ambiental, estando submetido a risco pequeno de deterioração da estrutura.

Os elementos estruturais do pavilhão foram identificados da seguinte forma:

(a) placas de vedação do tipo "A", elementos do eixo longitudinal do pavilhão enumerados de A1 a A178;

(b) placas de vedação do tipo "B", elementos do eixo transversal enumerados de B1 a B33;

(c) placas de vedação do tipo “C”, elementos das laterais imediatas das portas enumerados de $\mathrm{C} 1 \mathrm{a}$ C8; e (d) vigas protendidas, enumeradas de V1 a V77 (Figura 9). Os tipos de danos encontrados estão listados na seção de resultados e discussões.

O Roteiro de Inspeções apresenta tabelas com os valores de fator de ponderação (Fp) para cada dano, responsável por caracterizar a gravidade do dano em função do elemento estrutural em que se manifesta, assim como tabelas e imagens que auxiliam na determinação do respectivo fator de intensidade (Fi), que caracteriza a intensidade do dano conforme avaliação visual. O grau de dano (D) é calculado em função de $\mathrm{Fp}$ e Fi, representando a porção de dano a ser considerada no elemento em função de uma única manifestação patológica, conforme Equações 1 ou 2; já o grau de deterioração de um elemento (Gde) deve ser encontrado em função dos graus de dano de todas as manifestações encontradas na mesma peça estrutural, de acordo com a Equação 3.

Posteriormente, determina-se, por meio da Equação 4, o grau de deterioração de uma família de elementos (Gdf) em função de todos os Gde que compreendem aquela família; por fim, determina-se o grau de deterioração da estrutura (Gd) através da Equação 5. Para ser determinado este último é preciso relacionar os Gdf com o fator de relevância estrutural (Fr) de cada família, que varia de 1 a 5 , conforme a importância da família de elementos no comportamento e no desempenho da estrutura. Para vigas e pilares principais, valores aplicáveis ao SG10, o Fr é igual a 5,0. Todas as formulações para cálculos das variáveis e determinação dos danos estão apresentadas das Equações 1 a 5.

$$
\begin{aligned}
& D=0,8 F i F p \text { para } F i \leq 2,0 \\
& \text { Eq. } 1 \\
& D=(12 F i-28) F p \text { para } F i>2,0 \\
& G d e=D m a ́ x\left[1+\frac{\sum_{i=1}^{m} D(i)-D m a ́ x}{\sum_{i=1}^{m} D(i)}\right] \\
& G d f=G d e m a ́ x\left[\sqrt{1+\frac{\sum_{i=1}^{m} \operatorname{Gde}(i)-G d e m a ́ x}{\sum_{i=1}^{m} \operatorname{Gde}(i)}}\right] \quad \text { Eq. } 4 \\
& G d=\frac{\sum_{i=1}^{m} F r(i) G d f(i)}{\sum F r(i)} \\
& \text { Eq. } 5 \\
& \text { Eq. } 2 \\
& \text { Eq. } 3
\end{aligned}
$$


Figura 9 - Identificação dos elementos estruturais do SG-10

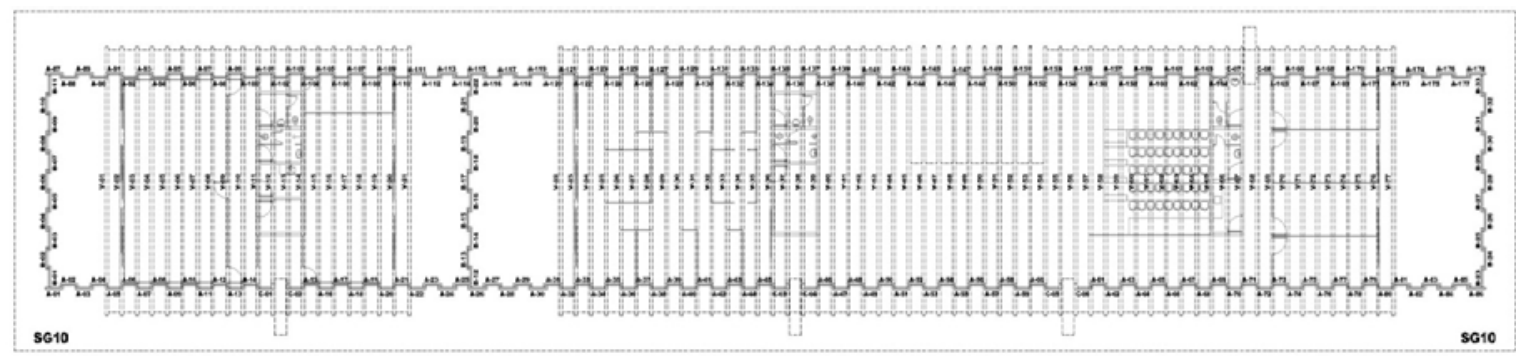

Fonte: adaptada de Prefeitura do Campus (2016).

\section{Resultados e discussões \\ Grau de deterioração dos elementos (Gde) e famílias (Gdf)}

Os resultados dos cálculos de Gde e Gdf, obtidos por meio de levantamentos in loco das manifestações patológicas nos elementos estruturais, estão apresentados na Tabela 1. Observa-se que a maioria dos elementos se enquadra em níveis de deterioração baixo e médio, entretanto os poucos elementos que estão em estado sofrível ou crítico majoram o resultado final do cálculo. Duas das quatro famílias apresentaram Gde máximos considerados críticos, o que eleva o grau de deterioração da estrutura.

A família de placas A, por exemplo, possui apenas $5 \%$ dos elementos entre os níveis sofrível e crítico, enquanto $95 \%$ se enquadram entre baixo e médio; ainda assim, seu Gdf é igual a 223,29. A família de placas B, mesmo possuindo $94 \%$ de seus elementos nos níveis médio e alto, apresentou elevado nível de deterioração $(219,89)$ devido à existência de $6 \%$ de elementos em estado crítico. Sendo constituída por $88 \%$ dos elementos em nível baixo e por $13 \%$ em nível alto, a família de placas $\mathrm{C}$ atingiu nível de deterioração de 75,1. Por fim, a família de vigas possui $82 \%$ dos elementos nos níveis baixo e médio e $18 \%$ nos níveis alto e sofrível, atingindo 122,75 de nível de deterioração. As porcentagens estão listadas na Figura 10.

Com base nos resultados apresentados, elaborou-se um mapeamento dos níveis de deterioração dos elementos da estrutura do SG-10. As Figuras 11 e 13 apresentam respectivamente os mapeamentos dos estados de degradação das placas e das vigas. Nota-se que a maioria das placas se encontra em nível baixo de deterioração, no entanto as que estão em estado sofrível ou crítico, mesmo sendo em menor número, elevam o Gd do edifício. As placas com elevados níveis de deterioração apresentaram maior incidência de manifestações patológicas da ordem de exposição das armaduras em estado avançado de corrosão (Figuras 12a e 12b), carbonatação (Figura 12b), desplacamentos (Figuras 12b e 12c), umidade excessiva na base (Figura 12b) e, consequentemente, cobrimento deficiente.

No que diz respeito às vigas do edifício, a maior incidência patológica se concentra nos elementos localizados nas regiões de maior exposição às intempéries. Nessas vigas os índices de carbonatação, eflorescência e umidade se apresentaram em estado avançado, o que compromete a integridade do concreto e leva a família a atingir elevado valor de Gdf.

A Figura 14 apresenta vigas localizadas na região do jardim do Centro de Planejamento e uma peça no extremo do edifício. Por estarem mais expostos às ações climáticas, esses elementos acabam apresentando manifestações patológicas em estado mais crítico do que os elementos localizados nas regiões onde há forro de cobertura.

\section{Grau de deterioração da estrutura (Gd)}

O grau de deterioração da estrutura é resultado da relação existente entre os graus de deterioração das famílias de elementos do edifício e seus respectivos fatores de relevância estrutural. O SG-10, em função de seu sistema construtivo, possui elementos (placas e vigas) de mesma relevância e, segundo Fonseca (2007), todos pertencem à classe de vigas e pilares principais, com $\mathrm{Fr}=5,0$. A Tabela 2 mostra os níveis de deterioração de uma estrutura, suas respectivas ações a serem adotadas em casos de intervenção e o Gd do SG-10. 
Tabela 1 - Gde e Gdf dos elementos do SG-10

\begin{tabular}{|c|c|c|c|c|c|c|}
\hline \multirow{2}{*}{$\begin{array}{c}\text { Nível de } \\
\text { deterioração }\end{array}$} & \multirow[b]{2}{*}{ Gde } & \multicolumn{4}{|c|}{ Número de elementos das famílias } & \multirow[b]{2}{*}{ Ações } \\
\hline & & $\begin{array}{c}\text { Placa } \\
\text { A }\end{array}$ & $\begin{array}{c}\text { Placa } \\
\text { B }\end{array}$ & $\begin{array}{c}\text { Placa } \\
\text { C }\end{array}$ & Viga & \\
\hline Baixo & $0-15$ & 109 & 0 & 7 & 41 & $\begin{array}{l}\text { Estado aceitável. Manutenção } \\
\text { preventiva. }\end{array}$ \\
\hline Médio & $15-50$ & 60 & 28 & 0 & 22 & $\begin{array}{l}\text { Definir prazo/natureza para nova } \\
\text { inspeção. Planejar intervenção em } \\
\text { longo prazo (máx. } 2 \text { anos). }\end{array}$ \\
\hline Alto & $50-80$ & 0 & 3 & 1 & 1 & $\begin{array}{l}\text { Definir prazo/natureza para inspeção } \\
\text { especializada detalhada. Planejar } \\
\text { intervenção em médio prazo (máx. } 1 \\
\text { ano). }\end{array}$ \\
\hline Sofrível & $\begin{array}{l}80- \\
100\end{array}$ & 5 & 0 & 0 & 13 & $\begin{array}{l}\text { Definir prazo/natureza para inspeção } \\
\text { especializada detalhada. Planejar } \\
\text { intervenção em curto prazo (máx. } 6 \\
\text { meses). }\end{array}$ \\
\hline Crítico & $>100$ & 4 & 2 & 0 & 0 & $\begin{array}{l}\text { Inspeção especial emergencial. } \\
\text { Planejar intervenção imediata. }\end{array}$ \\
\hline \multicolumn{2}{|c|}{$\mathrm{N}^{0}$ total de elementos } & 178 & 33 & 8 & 77 & \\
\hline \multicolumn{2}{|c|}{ Gde máximo } & 159,55 & 160,32 & 60,95 & 87,63 & \\
\hline \multicolumn{2}{|c|}{ Gdf } & 223,29 & 219,89 & 75,10 & 122,75 & \\
\hline
\end{tabular}

Figura 10 - Porcentagens dos elementos por níveis de deterioração

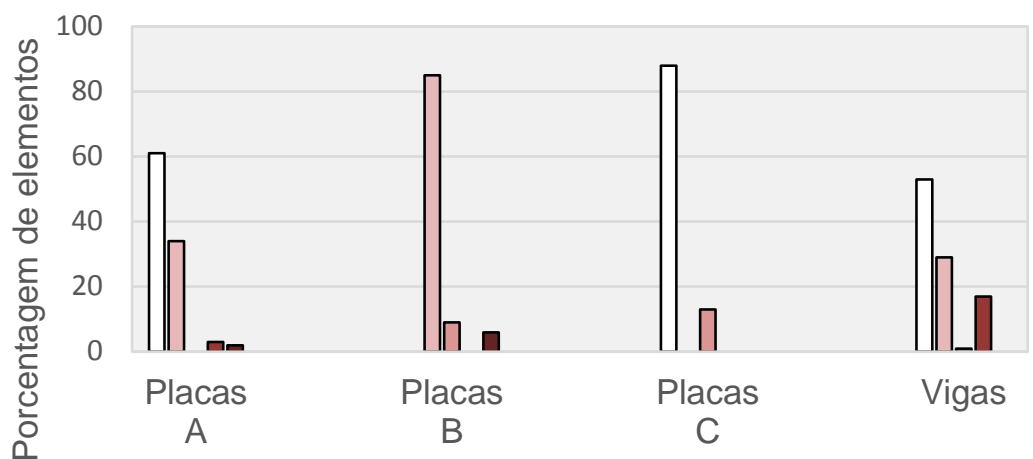

Famílias de elementos

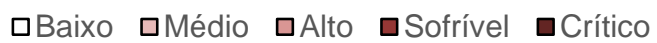

Figura 11 - Mapeamento dos níveis de deterioração das placas

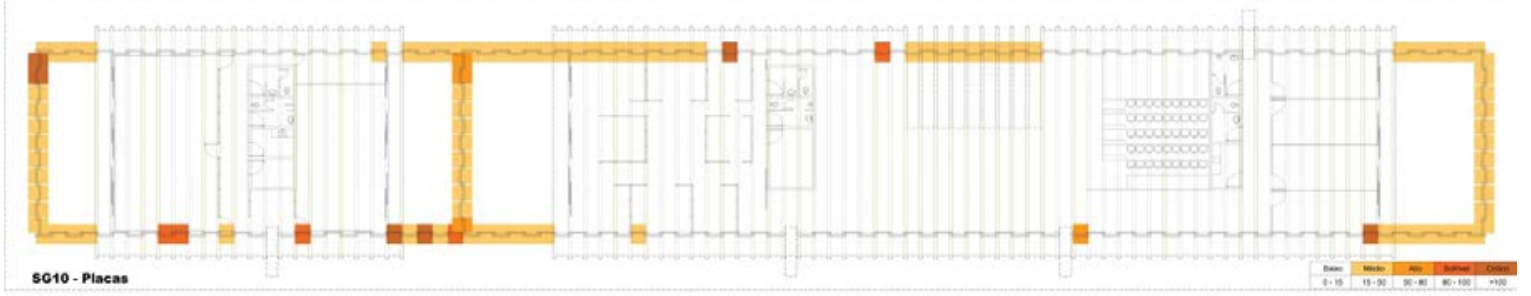

Fonte: adaptada de Prefeitura do Campus (2016). 
Figura 12 - Manifestações patológicas nas placas A (a), B (b) e C (c)

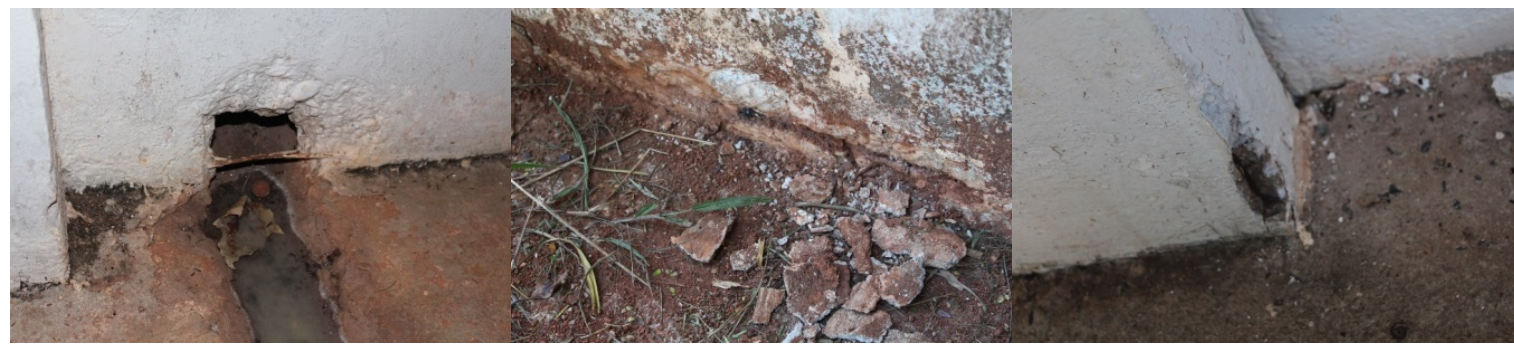

(a)

(b)

(c)

Figura 13 - Mapeamento dos níveis de deterioração das vigas

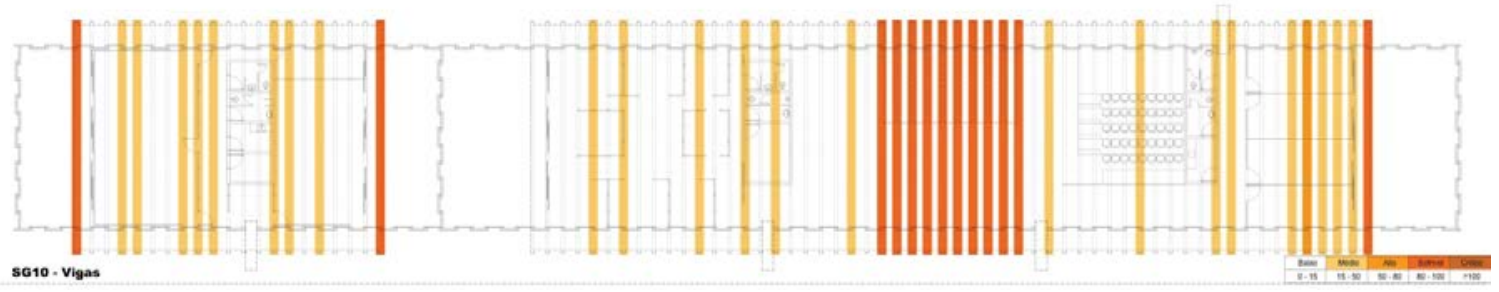

Fonte: adaptada de Prefeitura do Campus (2016).

Figura 14 - Manifestações patológicas nas vigas

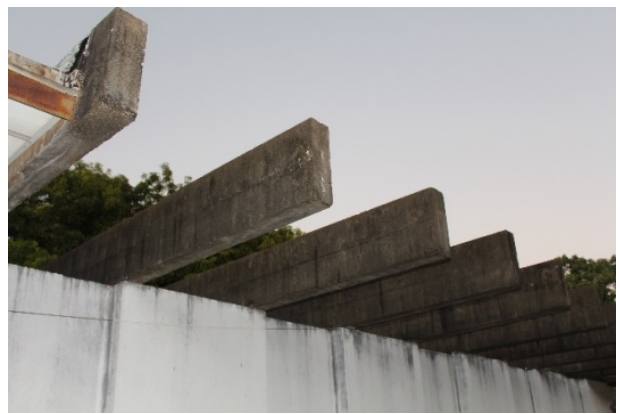

(a)

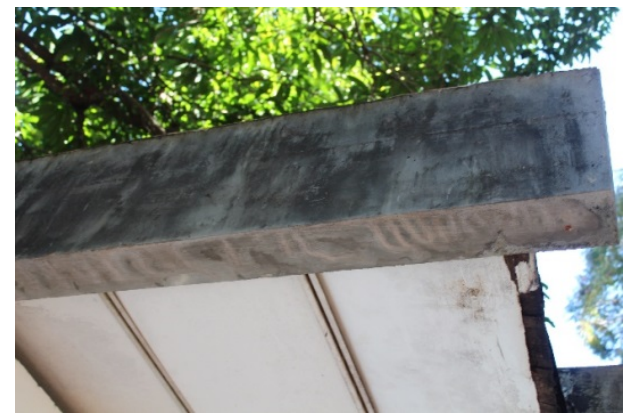

(b)

Tabela 2 - Grau de deterioração da estrutura do SG-10

\begin{tabular}{c|c|c|l}
\hline $\begin{array}{c}\text { Gd } \\
\text { SG-10 }\end{array}$ & $\begin{array}{c}\text { Nível de } \\
\text { deterioração }\end{array}$ & Gd & \multicolumn{1}{c}{ Ações } \\
\hline \multirow{4}{*}{$\mathbf{1 6 0 , 2 7}$} & Baixo & $0-15$ & Estado aceitável. Manutenção preventiva. \\
\cline { 2 - 5 } & Médio & $15-50$ & $\begin{array}{l}\text { Definir prazo/natureza para nova inspeção. Planejar intervenção } \\
\text { em longo prazo (máx. 2 anos). }\end{array}$ \\
\cline { 2 - 5 } & Alto & $50-80$ & $\begin{array}{l}\text { Definir prazo/natureza para inspeção especializada detalhada. } \\
\text { Planejar intervenção em médio prazo (máx. 1 ano). }\end{array}$ \\
\cline { 2 - 5 } & Sofrível & $\begin{array}{c}80- \\
100\end{array}$ & $\begin{array}{l}\text { Definir prazo/natureza para inspeção especializada detalhada. } \\
\text { Planejar intervenção em curto prazo (máx. 6 meses). }\end{array}$ \\
\cline { 2 - 5 } & Crítico & $>\mathbf{1 0 0}$ & Inspeção especial emergencial. Planejar intervenção imediata. \\
\hline
\end{tabular}

O edifício atingiu $\mathrm{Gd}=160,27$, ou seja, apresentouse em estado crítico de deterioração, o que exige inspeção especial emergencial e plano de intervenção imediato. Esse valor é resultado da incidência de manifestações patológicas com elevados fatores de ponderação, como existência de vários pontos de exposição de armaduras em processo avançado de corrosão; recalque da estrutura na região do auditório (Figura 16); umidade excessiva; e carbonatação e desplacamento em quase todos os elementos da estrutura.

Diante do resultado apresentado, o edifício do SG10 precisa passar por um processo de intervenção 
imediato, sendo necessária a realização de serviços de recuperação da estrutura. Para que haja sucesso na recuperação é fundamental conhecer todas as suas etapas, que as atividades sejam realizadas por profissionais habilitados e que sejam aplicados produtos de alta qualidade. As imagens apresentadas na seção a seguir incluem as manifestações patológicas de maior intensidade encontradas durante as vistorias realizadas na edificação.

Nos elementos com armadura exposta, em que não houve perda de seção transversal do aço em função da corrosão (Figura 18), a execução dos reparos pode ser realizada com processos convencionais, nos quais as técnicas consistem na aplicação de proteção anticorrosiva, que tem a função de proteger a armadura desacelerando os processos de corrosão; de ponte de aderência, responsável por aumentar a aderência entre o substrato e a argamassa; e de argamassa polimérica, camada com função de preencher os vazios, que tem alta resistência e pode ser modificada com fibras.

Nos elementos que apresentam fissuração em estado estável, verificado por meio da disposição de massa de gesso sobre a fissura, indica-se o uso de processos de reparos rápidos com argamassa fluida. A fissura apresentada nas Figuras 15a a 15c encontra-se estabilizada, devendo apenas passar pelo processo de preenchimento. Caso fosse encontrada alguma fissura que ainda se apresentasse instável, a causa da continuidade da abertura deveria ser identificada e solucionada, e posteriormente o preenchimento deveria ser realizado. Geralmente, os fabricantes indicam esse tipo de produto, que possui elevada resistência e bom tempo de trabalhabilidade, para reparos de vazios de até $50 \mathrm{~mm}$.

Nos elementos com armadura exposta em que houve perda de seção transversal (Figura 16) indicase a escarificação da camada superficial de concreto em profundidade de 2,0 cm a 5,0 cm (SOUZA; RIPPER, 2009) para a realização de reparos semiprofundos com substituição parcial da barra de aço corroída e a realização da ancoragem da nova armadura com procedimentos subsequentes descritos no parágrafo anterior.

Após a realização das medidas de reparo, de forma a prolongar a vida útil de serviço da edificação, é indicada a proteção da estrutura com processos que incluem a escamação das camadas de tinta já executadas para aplicação de revestimentos epóxi isentos de solventes com elevada resistência química, que, além de garantir a resistência química a ácidos, álcalis, óleos e outros, também garantirá impermeabilidade à água e ao vapor d’água, dispensando a aplicação de primer. Esses procedimentos devem ser seguidos da aplicação de pintura, que deve ser vistoriada e passar por manutenções rotineiras. A camada de tinta caracteriza mais uma faixa de proteção dos elementos, o que dificulta a penetração de agentes agressivos do ambiente e aumenta a resistência às intempéries. Nenhum desses procedimentos impacta nas intenções de projeto de Niemeyer.

\section{Levantamento fotográfico das manifestações patológicas}

De forma a apresentar as manifestações patológicas encontradas com a aplicação da metodologia, abaixo é apresentado o relatório fotográfico resultante do levantamento in situ. Os procedimentos de correção dessas manifestações devem seguir o especificado na seção anterior, segundo o que a intensidade do dano apresentado pela estrutura é vinculada ao procedimento mais adequado para a solução de cada problema.

As Figuras 16a a 16c apresentam imagens que retratam desplacamento da camada superficial do concreto causada pela corrosão acentuada das armaduras em diferentes paredes da edificação. A corrosão pôde ter sido causada pela carbonatação do concreto, o que permitiu que a armadura fosse despassivada. Uma vez nessa condição, a armadura entrou em processo de corrosão, expandindo e expulsando a camada de concreto de proteção, como pode ser bem visualizado pela configuração dos desplacamentos que seguem o posicionamento das armaduras.

As Figuras 17a e 17c apresentam imagens de vigas com impermeabilização deficiente, visível pela presença de manchas escuras resultantes da umidade; falhas de concretagem, visíveis pela exposição dos agregados na face inferior da viga da Figura 17b, resultantes de um possível processo deficiente de adensamento do concreto durante a concretagem das peças; e lixiviação, causada pela impermeabilização falha, que gerou eflorescências (manchas esbranquiçadas), conforme apresentado na Figura 17c.

Por fim, as Figuras 18a e 18c também apresentam manchas causadas pela umidade e pela falta de impermeabilização nas peças estruturais, além de peças com desvio de geometria, visível pelo distanciamento entre as placas de vedação (Figura 18b). O desvio de geometria pode vir a permitir o acúmulo de água, o que aumenta os riscos de deterioração das peças em locais não visíveis e impossibilita a detecção das manifestações patológicas em fases iniciais. O desplacamento apresentado na Figura 18a se apresenta como resultado do avanço de uso indevido da edificação, tendo sido causado, possivelmente, por ação 
mecânica. Entretanto, a ausência dessa camada protetora da armadura pode desencadear outras manifestações já citadas, devendo ser tratada da mesma forma que os desplacamentos causados pela expansão das armaduras em processo de corrosão.

\section{Considerações finais}

Este artigo se fundamentou na análise do estado de conservação dos elementos da estrutura do edifício SG-10 do complexo da Universidade de Brasília, aplicando-se a metodologia GDE/UnB, com a qual se constatou que ele se encontra em nível de deterioração crítico, o que corresponde à não delimitação de um prazo, mas de uma ação de intervenção imediata por parte da instituição. As técnicas de reparo indicadas devem ser realizadas por profissionais habilitados, mesmo que sejam fáceis e rápidas de serem executadas.

Os mapeamentos dos níveis de deterioração dos elementos componentes da estrutura apresentados neste artigo constituem um documento de direcionamento das intervenções que auxiliará na localização das placas e vigas que estão em estados mais avançados de degradação e que, portanto, poderá, como uma proposta metodologicamente estruturada, orientar os profissionais responsáveis no momento do planejamento e execução das intervenções.

Figura 15 - Fissura resultante do recalque na região do auditório

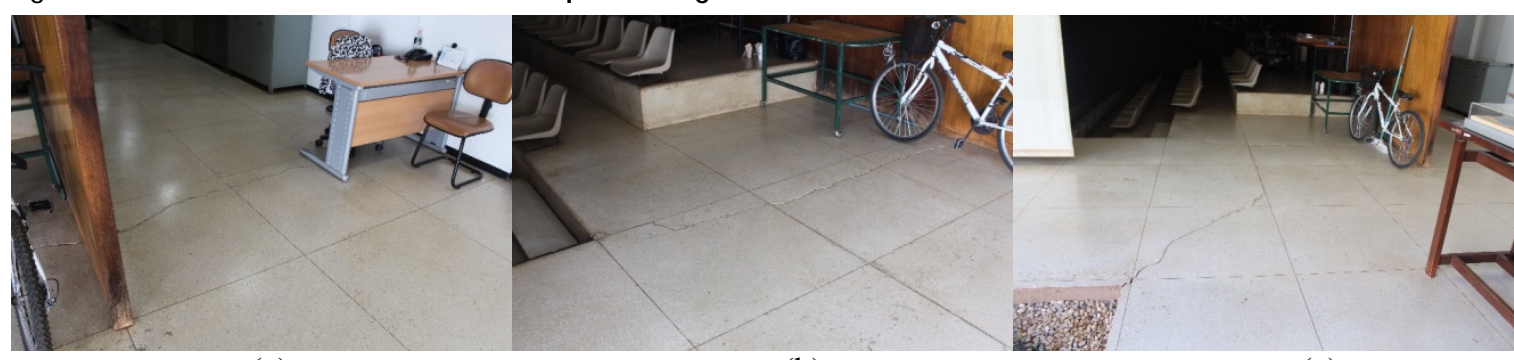

(a)

(b) (c)

Figura 16 - Placas com desplacamento, cobrimento deficiente e corrosão das armaduras

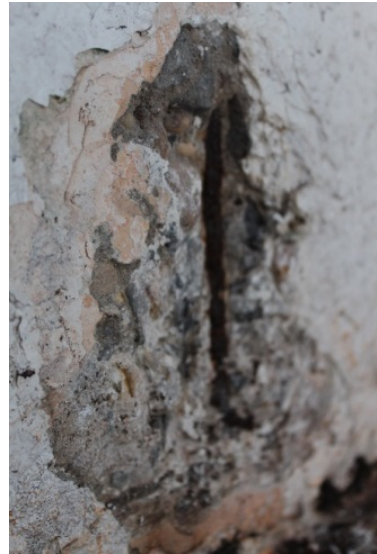

(a)

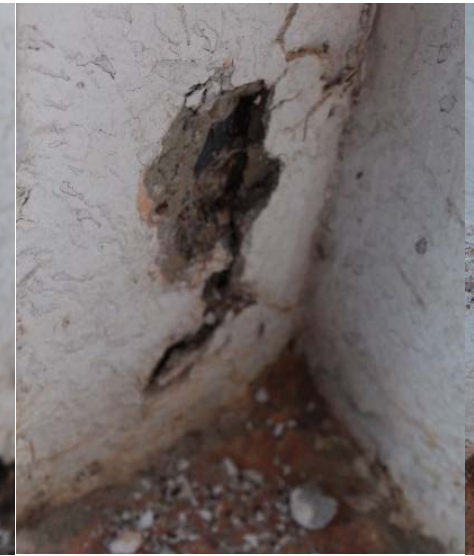

(b)

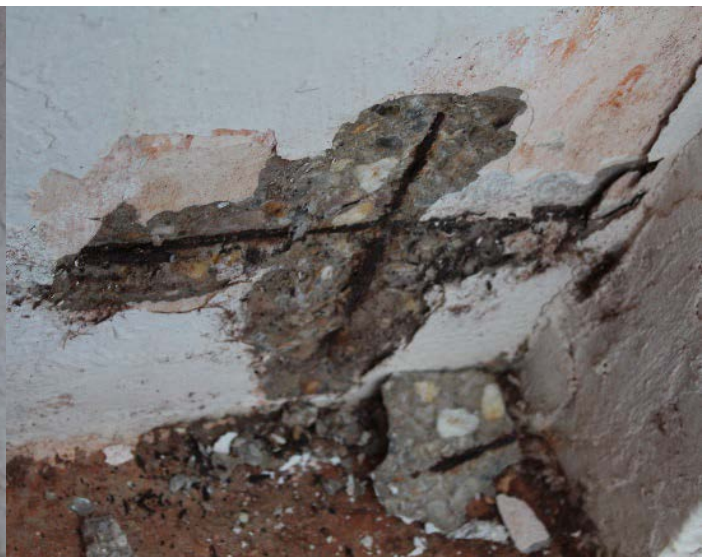

(c)

Figura 17 - Vigas com impermeabilização deficiente (a), segregação e falha de concretagem (b) e umidade, carbonatação e eflorescência (c)

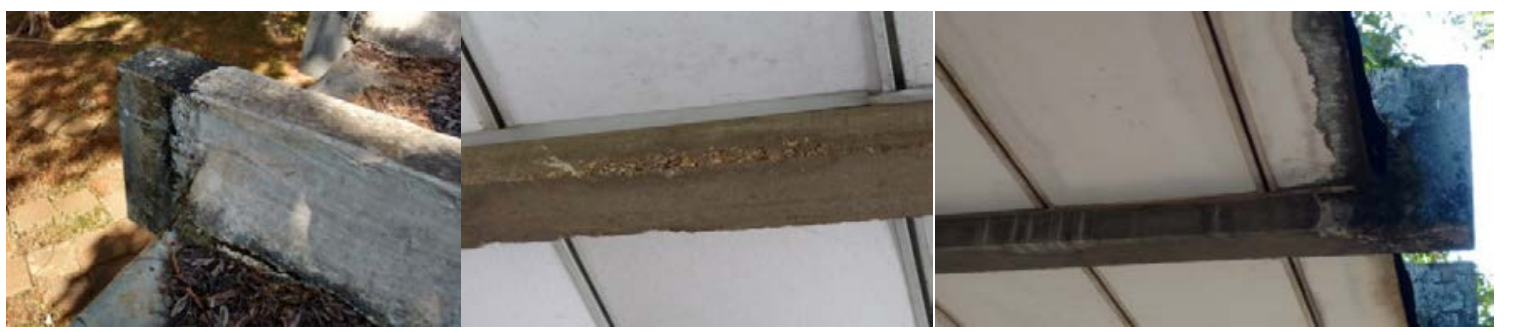

(a)

(b)

(c) 
Figura 18 - Placas com desplacamento do concreto (a), desvios de geometria (b) e umidade na base (c)

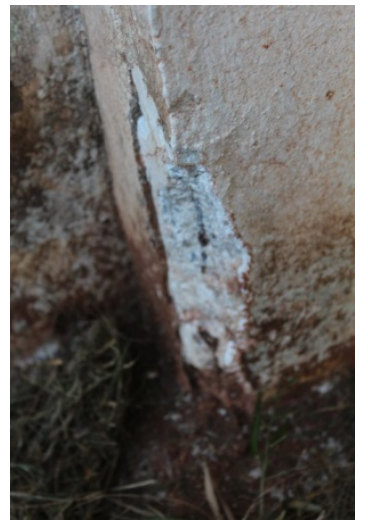

(a)

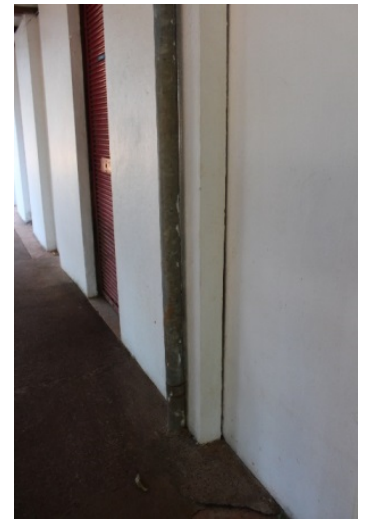

(b)

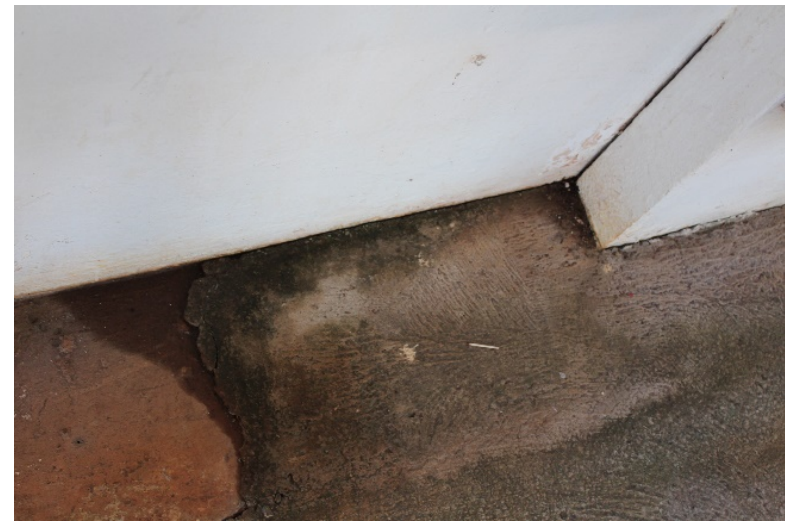

(c)

A conservação desse edifício é de fundamental importância para a preservação da memória da universidade, visto que ele faz parte do conjunto de edificações mais antigas e importantes do complexo, além de abrigar o Centro de Planejamento da instituição. Cabe ao setor responsável pela manutenção instaurar uma cultura de manutenções corretivas e, posteriormente, rotineiras e preventivas, aplicando os métodos indicados ou outras formas que se enquadrem aos processos internos, que colaborem com a durabilidade não só dessa edificação, mas de todas as que compõem a universidade.

\section{Referências}

ASSOCIAÇÃO BRASILEIRA DE NORMAS

TÉCNICAS. NB-1: cálculo e execução de obras de concreto armado. Rio de Janeiro, 1960.

\section{ASSOCIAÇÃO BRASILEIRA DE NORMAS \\ TÉCNICAS. NBR 5674: manutenção de} edificações: requisitos para o sistema de gestão de manutenção. Rio de Janeiro, 2012.

\section{ASSOCIAÇÃO BRASILEIRA DE NORMAS TÉCNICAS. NBR 6118: projeto de estruturas de concreto: procedimento. Rio de Janeiro, 2014.}

BOLDO, P. Análise Quantitativa de Estruturas de Concreto Armado de Edificações no Âmbito do Exército Brasileiro. Brasília, 2002. 295 f. Dissertação (Mestrado em Engenharia Civil e Ambiental) - Faculdade de Tecnologia, Universidade de Brasília, Brasília, 2002.

CASTRO, E. K. Desenvolvimento de Metodologia Para Manutenção de Estruturas de Concreto Armado. Brasília, 1994. 139 f. Dissertação (Mestrado em Engenharia Civil) Faculdade de Tecnologia, Universidade de Brasília, Brasília, 1994.

CZARNECKI, L.; WOYCIECHOWSKI, P. Prediction of the Reinforced Concrete Structure Durability Under the Risk of Carbonation and Chloride Aggression. Bulletin of the Polish Academy of Sciences, Philadelphia, v. 61, n. 1, p. 173-181, 2013.

FONSECA, R. P. A Estrutura do Instituto Central de Ciências: aspectos históricos, científicos e tecnológicos de projeto, execução, intervenções e propostas de manutenção. Brasíla, 2007. 213 f. Dissertação (Mestrado em Engenharia Civil) - Departamento de Engenharia Civil e Ambiental, Universidade de Brasília, Brasília, 2007.

MOREIRA, F. D. Os Desafios Postos Pela Conservação da Arquitetura Moderna. Revista CPC, Universidade de São Paulo, n. 11, 2011.

NIEMEYER, O. Galpão Para Serviços Gerais II. Revista Acrópole, v. 369/370, p. 42-43, 1970.

PREFEITURA DO CAMPUS. Projeto Arquitetônico do SG 10 - Centro de Planejamento Oscar Niemeyer/Núcleo de Vivência. Autoria original de Oscar Niemeyer. Versão atualizada em 2010. Brasília: Prefeitura da Universidade de Brasília, 2016. Plantas diversas. Originalmente disponibilizadas por meio eletrônico.

ROUGEAU, P.; GUIRAUD, P. A Durabilidade no Contexto Normativo Europeu. In: CASCUDO, O.; CARASEK, H. (Eds.). Durabilidade do

Concreto: bases científicas para formulação de concretos duráveis de acordo com o ambiente. São Paulo: IBRACON, 2014.

SCHLEE, A. R. et al. Registro Arquitetônico da Universidade de Brasília. Brasília: Ed. da UnB, 2014. 
SOUZA, V. C. M.; RIPPER, T. Patologia, Recuperação e Reforço de Estruturas de Concreto. São Paulo: Pini, 2009.
TRENTIN, P. O Patrimônio Cultural Edificado e Sua Gestão: a preservação e conservação do patrimônio histórico na cidade moderna.

Vitruvius: Drops, São Paulo, v. 6, n. 012.05, 2005.

\section{Tiago Ferreira Campos Neto}

Programa de Pós-Graudação em Arquitetura e Urbanismo, Faculdade de Arquitetura e Urbanismo | Universidade de Brasília | Rua 55, 400, Setor Central | Goiânia - Goiás - Brasil | CEP 74055-150 | Tel.: (62) 98101-0095 | E-mail: tiagocampos.eng@gmail.com

\section{J éssica Brandão Faria}

Programa de Pós-Graudação em Arquitetura e Urbanismo, Faculdade de Arquitetura e Urbanismo Universidade de Brasília | Campus Universitário Darcy Ribeiro, Asa Norte | Brasília - DF - Brasil | CEP 70910-900 | Tel.: (35) 99948-2787 |

E-mail: jessicaabrandao@gmail.com

\section{J osé Manoel Morales Sánchez}

Departamento de Tecnologia em Arquitetura e Urbanismo, Faculdade de Arquitetura e Urbanismo | Universidade de Brasília | Campus Universitário Darcy Ribeiro, Asa Norte | Brasília - DF - Brasil | CEP 70910-900 | Tel.: (61) 3197-6630 | E-mail: sanchez@unb.br

\section{João da Costa Pantoja}

Departamento de Tecnologia em Arquitetura e Urbanismo, Faculdade de Arquitetura e Urbanismo | Universidade de Brasília | Campus Universitário Darcy Ribeiro, Asa Norte | Brasília - DF - Brasil | CEP 70910-900 | Tel.: (61) 3340-1945 | E-mail: joaocpantoja@gmail.com

\section{Revista Ambiente Construído}

Associação Nacional de Tecnologia do Ambiente Construído

Av. Osvaldo Aranha, 99 - 3o andar, Centro

Porto Alegre - RS - Brasil

$$
\text { CEP } 90035-190
$$

Telefone: +55 (51) 3308-4084

Fax: +55 (51) 3308-4054

www. seer. ufrgs. br/ ambienteconstruido

E-mail: ambienteconstruido@ufrgs.br

(c) () 